\title{
CliNICAL AND LABORATORY ASPECTS OF A TRICHINELLOSIS OUTBREAK IN IZMIR, TURKEY
}

\author{
TURK M.*, KAPTAN F.**, TURKER N.**, KORKMAZ M.***, EL S.**, OZKAYA D.**, URAL S.**, VARDAR I.**, \\ ALKAN M.Z.***, COSKUN N.A.**, TURKER M.* \& POZIO E.****
}

\section{Summary:}

Epidemiological, clinical and laboratory data were collected during an outbreak of trichinellosis, which occurred in Izmir, Turkey, between January and March 2004. The source of the infection was raw meatballs made with a mixture of uncooked beef and pork. Of 474 persons who were admitted at the Ataturk Training and Research Hospital during this period with a history of raw meatball consumption, the diagnosis of trichinellosis was confirmed for 154 132.5\%, 87 males and 67 females; mean age 31 years, range $6-67$ years). Among persons with a confirmed diagnosis, $79 \%$ had myalgia, $77 \%$ weakness and malaise, $63 \%$ arthralgia, $40 \%$ jaw pain, $68 \%$ fever, $63 \%$ periorbital and/or facial oedema, $49 \%$ oedema at the trunk and limb, $42 \%$ abdominal pain, $40 \%$ nausea and vomiting, $28 \%$ diarrhoea, $23 \%$ subconjunctival haemorrhage, $25 \%$ macular or petechial rash, $4 \%$ subungual haemorrhage, $15 \%$ cardiac complaints and $0.2 \%$ neurological complaints. Nine patients $(5.8 \%)$ were hospitalised due to severe myalgia $(n=2)$, high fever $(n=3)$, neurological manifestations ( $n=1)$, thrombophlebitis $(n=2)$ and palmar erythema $(n=1)$. Eosinophilia was present in $88 \%$ of the confirmed cases at the admission. Elevated levels of serum creatine phosphokinase, lactic dehydrogenase and aspartate aminotransferase were detected in $72 \%, 70 \%$ and $16 \%$ of the confirmed cases, respectively. The seroconversion occurred in most of the infected people between the $4^{\text {th }}$ and $6^{\text {th }}$ weeks after the infection. All of the confirmed cases were treated with mebendazole. People with severe symptoms were treated also with prednisolone

$160 \mathrm{mg} /$ day for three days) and those with a moderately severe clinical pattern received a non-steroid anti-inflammatory drug (naproxen sodium, $550 \mathrm{mg} /$ day). All confirmed cases recovered without any clinical sequela.

KEY WORDS : trichinellosis, Trichinella britovi, outbreak, symptomatology, laboratory and epidemiological features, raw meatballs, pork, beef, Turkey.

* Laboratory of Clinical Microbiology, and ** Department of Infectious Diseases, Atatürk Training and Research Hospital, Izmir, Turkey. **** Department of Parasitology, Ege University Medical School, Bornova, Izmir, Turkey.

**:** Department of Infectious, Parasitic and Immunomediated Diseases, Istituto Superiore di Sanità, Rome, Italy.

Correspondence: Dr. Meral Turk, Atatürk Training and Research Hospital, Laboratory of Clinical Microbiology, Denizli State Hospital - Laboratory of Clinical Parasitology / Denizli, Izmir, Turkey. Tel: +90-232-244 $4444 /+90-258-2639311$.

Fax: +90-232-388 1347 / +90-258-2619206

E-mail: turkmeral@hotmail.com
Résumé : ASPECTS CLINIQUES ET BIOLOGIQUES D'UNE ÉPIDÉMIE DE TRICHINELLOSE À IZMir, EN TURQUie

Les données épidémiologiques, cliniques et biologiques ont été collectées pendant une épidémie de trichinellose qui a eu lieu à Izmir, Turquie, entre janvier et mars 2004. L'infection a été causée par des boulettes faites d'un mélange de viandes de bouf et de porc, consommées crues. 474 personnes ont été hospitalisées. Chez 154 d'entre elles $132,5 \%$; 87 hommes et 67 femmes; âge moyen de 31 ans : 6-67 ans) le diagnostic de trichinellose a été confirmé. Parmi elles : $79 \%$ présentaient des myalgies ; $77 \%$ un état de faiblesse et des malaises; $63 \%$ des arthralgies; $40 \%$ des douleurs de la mâchoire; $68 \%$ de la fièvre; $63 \%$ un cedème périorbitaire et/ou facial; $49 \%$ un oedème du tronc et des membres; $42 \%$ des douleurs abdominales; $40 \%$ des nausées et des vomissements; $28 \%$ une diarrée; $23 \%$ une hémorragie sousconjonctivale; $25 \%$ un exanthème maculaire ou pétéchial; $4 \%$ une hémorragie sublinguale; $15 \%$ des troubles cardiaques; et $0,2 \%$ des troubles neurologiques. Neuf patients $(5,8 \%)$ ont été hospitalisés à cause d'une myalgie sévère $(n=2)$, d'une fièvre élevée ( $n=3)$, de manifestations neurologiques ( $n=1)$, d'une thrombophlébite $(n=2)$ et d'un érythème palmaire $(n=1)$. L'hyperéosinophilie était présente dans $88 \%$ des cas confirmés à l'admission. Des taux élevés de créatine phosphokinase, de lactate déhydrogénase et d'aspartate aminotransférase sériques ont été détectés dans $72 \%, 70 \%$ et $76 \%$ des cas, respectivement. La séroconversion est survenue chez la plupart des personnes infectées entre la $4^{\mathrm{èm}}$ et la bème semaine après l'infestation. Tout les cas confirmés ont été traités par mébendazole. Les patients présentant des symptomes sévères ont reçu aussi de la prednisolone $160 \mathrm{mg} /$ jour pendant trois jours), et ceux présentant un tableau clinique moins sévère ont été traités avec du naproxène sodium $1550 \mathrm{mg} /$ /jour). Tous les cas confirmés ont montré une rémission de la symptomatologie sans aucune suite clinique.

MOTS CLÉS : trichinellose, épidemie, Trichinella britovi, symptomatologie, épidemiologie, diagnostic, boulette de viande crue, porc, boeuf, Turquie. 
et al., 2003). In Turkey, Trichinella infection is rare and had been reported in wild boars and humans (Nazli \& Inal, 1987). A large outbreak of trichinellosis occurred in Izmir after the consumption of raw meatballs made of beef and pork. The incriminated food was consumed mainly, during a religious holiday in December and at the New Year's dinner. The parasite isolated from infected meatballs and from human biopsies was identified as T. britovi (Ozdemir et al., 2005). The aim of the present study was to evaluate the clinical and laboratory features of people who were admitted at the Ataturk Training and Research Hospital (AT \& RH) of Izmir, Turkey, with a history of raw meatball consumption.

\section{PATIENTS AND METHODS}

\section{PATIENTS}

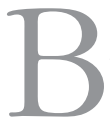

etween January and April 2004, all people who were admitted at the Infectious Diseases and the Clinical Microbiology Departments of the AT \& RH of Izmir with a history of consumption of raw meatballs, were enrolled in this study $(n=474)$. All persons underwent a complete physical examination. Individual data (i.e. age, sex, date of meatball consumption and its source) and the history of symptoms and signs were recorded. Time between the consumption of raw meatballs and the appearance of the first signs and symptoms was considered as the incubation period. During the acute phase of the outbreak, epidemiological, clinical and laboratory data were evaluated according to the algorithm suggested by Dupouy-Camet et al. (2002). Persons with a confirmed or a highly probable diagnosis of trichinellosis were treated with mebendazole $(25 \mathrm{mg} / \mathrm{kg}$, three times per day for two weeks). People with severe symptoms were treated also with prednisolone $(60 \mathrm{mg} /$ day for three days) and those with a moderately severe clinical pattern received a non-steroid anti-inflammatory drug (naproxen sodium, $550 \mathrm{mg}$ /day). All of the confirmed cases were followed by clinical examination and serology up to six months after the admission, but one patient, who was followed for one year.

\section{LABORATORY FEATURES}

Leukocyte and eosinophil counts were detected by the Cell-Dyn ${ }^{\circledR} 3700$ test kit (Abbott, USA), according to the manufacturer's instructions. Creatine phosphokinase (CPK), lactic dehydrogenase (LDH), aspartate amino transferase (AST) and albumin values were detected in sera of the patients by the Architect C $8000^{\mathrm{TM}}$ kit (Abbott, USA), according to the manufacturer's instructions. An ELISA kit (r-biopharm AG, RIDASCREEN ${ }^{\circledR}$
Trichinella IgG, Darmstadt, Germany), which uses a T. spiralis purified excretory/secretory antigen, was employed to detect anti-Trichinella antibodies in sera of enrolled people. Values $>1.1$ were considered as positive, according to the manufacturer's instructions. Haematological, biochemical and serological tests were performed on all enrolled persons $(n=474)$ at the admission and after 15, 30 and 60 days, and at six months post infection for those with a confirmed diagnosis. Muscle biopsies (1-2 g) were taken from the deltoid muscle $(\mathrm{n}=2)$ and from the gastrocnemius muscle $(n=1)$ of three persons four weeks after the onset of the symptoms. Each biopsy was cut into small pieces as the size of a rice grain, squashed between two microscope slides and examined for Trichinella larvae under a dissection microscope at $40 \times$ magnification.

\section{RESULTS}

$\mathrm{D}$ uring the acute phase of the outbreak of 474 persons with a history of raw meatball consumption, who were enrolled in this study, trichinellosis was confirmed for 154 (32.5\%), it was highly probable for $71(15.07 \%)$, probable for 60 (12.6\%), suspected for $42(8.9 \%)$ and very unlikely for 147 $(31.0 \%)$. On the basis of the clinical follow up and serology at six months p.i., trichinellosis was further confirmed for the 154 cases, because all of them showed a seroconversion (ELISA values $>1.1$ ), whereas all the other patients classified as "highly probable", "probable", "suspected" and "very unlikely" during the acute phase of the outbreak, were considered to be negative (ELISA values < 0.9). One Trichinella larva was detected in one biopsy (this patient with neurologic complications had always eaten raw meats) (Fig. 1). Among the 154 people with a confirmed diagnosis, 87 $(56.5 \%)$ were males and 67 (43.5\%) were females.

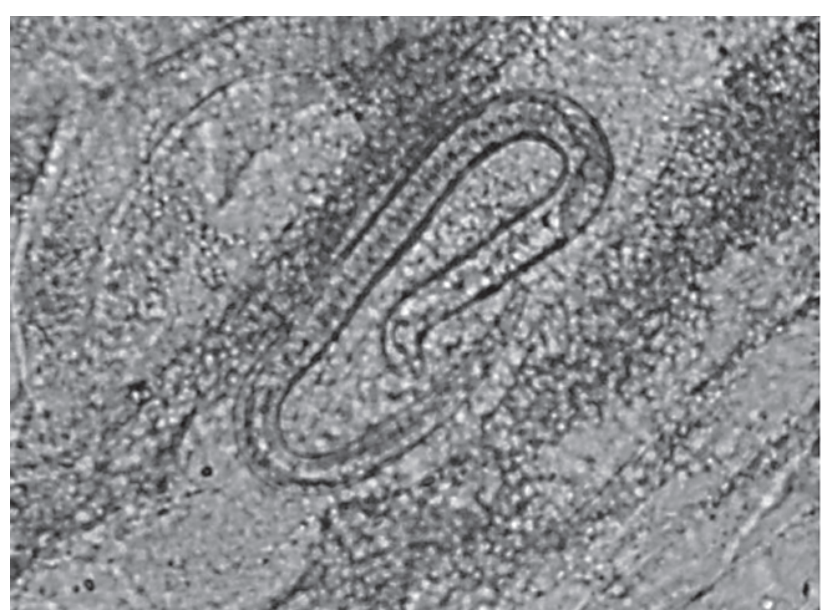

Fig. 1. - Trichinella larvae, detected in one case by trichinelloscopy. 


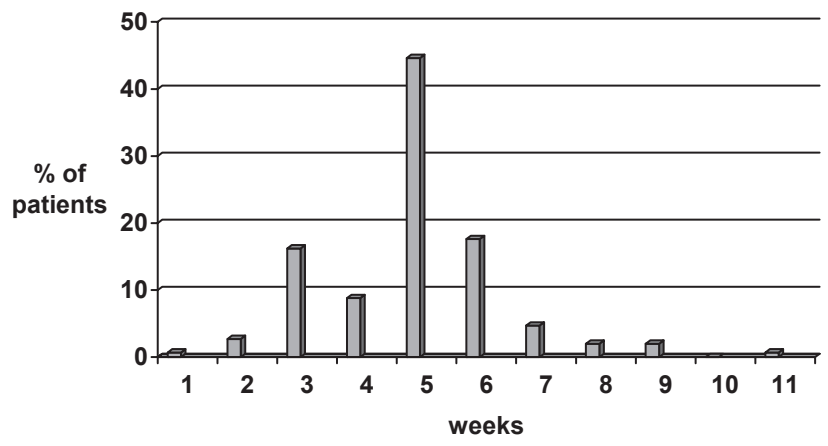

Fig. 2. - Percentage of patients $(n=148)$ with a confirmed diagnosis of trichinellosis showing different incubation periods (weeks).

Age range was 6-67 years (mean 31 years) with $71 \%$ of teenagers or young adults (10-39 years).

All confirmed cases had consumed raw meatballs in the same restaurant or bought from the same market. Furthermore, $80 \%$ of them had consumed the incriminated meatballs between December $16^{\text {th }}, 2003$ and January $1^{\text {st }}, 2004$.

The incubation period, known for 148 persons, ranged from five up to 76 days (average 31.8 days) after the consumption of raw meatballs (Fig. 2). Myalgia, weakness, malaise and fever were the most prominent sign and symptoms (Table I). The clinical pattern was classified as severe (5.8\%), moderately severe (46.1\%), benign (36.4\%), abortive (9.1\%) and asymptomatic $(2.6 \%)$. Nine people $(5.8 \%)$ were hospitalized due to severe myalgia $(n=2)$, uncontrolled fever $(n=3)$, neurological disorders $(n=1)$, thrombophlebitis $(n=2)$ and palmar erythema $(\mathrm{n}=1)$.

Eosinophilia was the most prominent laboratory finding detected in $88 \%$ of the confirmed cases at the admission and it was still present in $31 \%$ of them two

\begin{tabular}{lcc}
\hline \multicolumn{1}{c}{ Signs and symptoms } & No. (\%) & $\begin{array}{c}\text { Average weeks } \\
\text { (range) }\end{array}$ \\
\hline Myalgia & $122(79)$ & $5(2-8)$ \\
Weakness and malaise & $119(77)$ & $4(2-8)$ \\
Muscle weakness & $107(70)$ & $4(2-8)$ \\
Fever & $105(68)$ & $2(1-7)$ \\
Arthralgia & $97(63)$ & $1(1-3)$ \\
Periorbital oedema & $97(60)$ & $3(1-6)$ \\
Facial oedema & $93(60)$ & $2(1-4)$ \\
Headache & $93(60)$ & $2(2-6)$ \\
Trunk and limb oedema & $75(49)$ & $2(1-6)$ \\
Abdominal pain & $65(42)$ & $2(2-4)$ \\
Jaw pain & $61(40)$ & $2(2-6)$ \\
Nausea and vomiting & $61(40)$ & $1(1-3)$ \\
Conjunctival oedema & $58(38)$ & $1(1-4)$ \\
Cough & $55(36)$ & $1(1-3)$ \\
Itching & $49(32)$ & $1(1-3)$ \\
Diarrhea & $43(28)$ & $1(1-5)$ \\
Macular or petechial rash & $39(25)$ & $1(1-5)$ \\
Subconjunctival haemorrhage & $35(23)$ & $2(1-7)$ \\
Chest pain & $35(23)$ & $1(1-5)$ \\
Dispnea & $27(18)$ & $1(1-4)$ \\
Cardiac complaints & $23(15)$ & $2(1-6)$ \\
Disphagia & $21(14)$ & $1(1-6)$ \\
Subungual haemorrhage & $6(4)$ & $4(1-7)$ \\
Neurological complaints & $1(0.2)$ & 30 \\
& &
\end{tabular}

Table I. - Signs and symptoms of patients with confirmed trichinellosis $(n=154)$ and their frequency and length.

months later (Table II). High levels of CPK and LDH were detected in $71.4 \%$ and $72 \%$ of confirmed cases at the admission, respectively. The seroconversion occurred between the $2^{\text {nd }}$ and $8^{\text {th }}$ week after the infection. Anti-Trichinella IgG were detected in $42.2 \%$ of confirmed cases at the admission and increased to $67.8 \%$ and $73 \%$ after $15^{\text {th }}$ and $30^{\text {th }}$ days, respectively. Sixty days after the admission, all of the confirmed cases were seropositive (Table II) and a seropositive

\begin{tabular}{|c|c|c|c|c|}
\hline Laboratory tests & At admission & $15^{\text {th }}$ Day & $30^{\text {th }}$ Day & $60^{\text {th }}$ Day \\
\hline \multicolumn{5}{|l|}{ Leukocyte } \\
\hline Mean (range) cells $/ \mathrm{mm} 3$ & $11,211(4,300-27,300)$ & $9,060(4,060-16,400)$ & $8,340(4,070-17,700)$ & $7,750(3,940-15,500)$ \\
\hline$\%$ of persons $>10,000$ & 57.2 & 34 & 20.5 & 2.7 \\
\hline \multicolumn{5}{|l|}{ Eosinophil } \\
\hline Mean (range) per $\mu l$ & $2,046(46-17,810)$ & $1,842(34-6,270)$ & $1,112(28-5,671)$ & $569(11-1,768)$ \\
\hline$\%$ of persons $>400 \mu \mathrm{l}$ & 88 & 82.9 & 82.7 & 30.6 \\
\hline \multicolumn{5}{|l|}{ Creatine phosphokinase } \\
\hline Mean (range) U/L & $451(51-3,050)$ & $238(56-1,508)$ & $172(40-1,877)$ & $135(43-1,325)$ \\
\hline$\%$ of persons $>174 \mathrm{U} / \mathrm{L}$ & 71.4 & 48 & 27.6 & 11.8 \\
\hline \multicolumn{5}{|l|}{ Lactic dehydrogenase } \\
\hline Mean (range) U/L & $603(177-1,215)$ & $499(177-1,208)$ & $413(27-764)$ & $375(217-1,352)$ \\
\hline$\%$ of persons $>450 \mathrm{U} / \mathrm{L}$ & 72 & 61.2 & 26.7 & 16.7 \\
\hline \multicolumn{5}{|l|}{ Aspartate amino transferase } \\
\hline Mean (range) U/L & $39(13-312)$ & $30(14-135)$ & $29(12-155)$ & $31(11-167)$ \\
\hline$\%$ of persons $>37 \mathrm{U} / \mathrm{L}$ & 32.2 & 18.8 & 16.7 & 14.3 \\
\hline \multicolumn{5}{|l|}{ Anti-Trichinella IgG } \\
\hline$\%$ positive $>1.1$ & 42.2 & 67.8 & 73 & 100 \\
\hline$\%$ borderline $0.9-1.1$ & 7.8 & 7.4 & 9 & 0 \\
\hline$\%$ negative $<0.9$ & 50 & 24.8 & 18 & 0 \\
\hline
\end{tabular}

Table II. - Laboratory features of the confirmed cases of trichinellosis $(n=154)$ at the admission and 15,30 and 60 days after. 
ELISA test was also obtained for all of them, six months p.i. In four persons, the seroconversion occurred between three and 20 days before the appearance of the first signs and symptoms.

All persons with a confirmed diagnosis were treated with mebendazole. Nine people with severe symptoms received prednisolone and 71 people with a moderately severe clinical pattern received a non-steroid antiinflammatory drug. The compliance of the patients for the treatment was good. Most people with a confirmed diagnosis of trichinellosis recovered within a mean of 8 weeks (range three weeks-12 months) after infection without any clinical sequela. Only one patient with neurologic complications showed muscle weakness for eight months and fatigue for one year.

\section{DISCUSSION}

I $\mathrm{n}$ Turkey, raw meatballs made of minced meat, wheat, tomato paste and hot spices is one dish at risk for meat-borne infections. Traditionally, the source of the meat was the deer, but it has been replaced by beef for economic reasons. When a greedy producer added infected pork to beef meat, a large outbreak of trichinellosis occurred in the city of Izmir. The index case was admitted at the Dokuz Eylul University Hospital Clinic of Rheumatology on January 12, 2004 with the complaints of diffuse joint and muscle pain and fever for three weeks. Trichinellosis was suspected because of facial and periorbital oedema with eosinophilia. The detailed history revealed that she and her 13 friends had eaten together raw meatballs a month previously. Although all of these persons showed a similar symptomatology, the clinical pattern was misdiagnosed as a viral infection. On the $15^{\text {th }}$ of January, all of them (14 persons) had signs and symptoms and laboratory findings suggestive for trichinellosis (Ozdemir et al., 2005). The local health authorities were immediately alerted. Serological tests confirmed the diagnosis of trichinellosis of the index patient and her friends. The public health authorities confiscated the minced meat suspected to be the source of the infection and Trichinella larvae (6.5 larvae/g) were detected. The identification of animal proteins present in the minced meat revealed that both beef and pork were present. Trichinella larvae were also isolated from two muscle biopsies taken from the index case (7.7 larvae/g) and from another infected person (16.7 larvae/g) (Ozdemir et al., 2005). Larvae from both meatballs and human biopsies were identified as belonging to T. britovi (Ozdemir et al., 2005).

In Turkey up to date, only small-scale outbreaks of trichinellosis were documented and the last two occurred in Bursa in 2003 (seven infected people) and in Antalya in 2004 (more than 40 infected people) (Merdivenci et al., 1977; Bostan et al., 1999; Pozio \& Zarlenga, 2005). In 1987, Trichinella infection was documented in domestic and wild pigs and in pork products (Nazli \& Inal, 1987). Since the Muslim religion forbids the consumption of pork, this disease is very rare in the regions of the world where people obey its rules (Eisman \& Einat, 1992).

Trichinella britovi is the etiological agent of sylvatic trichinellosis in temperate regions of Europe, Asia, North and Western Africa (Pozio et al., 2005; Nezri et al., in press). The main hosts are carnivores (e.g. raccoon dogs, red foxes, golden jackals, wolves, brown bears and wild boars) (Pozio, 2000). Human infections caused by this species have been documented in Algeria, France, Italy, Slovak Republic and Spain (Lopez-Hernandez et al., 2000; Dubinsky et al., 2001; Pozio et al., 2001a; Cortes-Blanco et al., 2002; Gomez-Garcia et al., 2003; Herraez-Garcia et al., 2003; Rodriquez-Osorio et al., 2003; Gari-Toussaint et al., 2004; Rodriguez et al., 2004; Nezri et al., in press).

The clinical pattern observed during the course of this outbreak is similar to that of other outbreaks caused by the same species T. britovi (Gomez-Garcia et al., 2003). Sixty percent or more of persons with trichinellosis shared signs and symptoms (myalgia, weakness and malaise, muscle weakness, fever, arthralgia, periorbital oedema and headache) related to the muscle invasion, whereas only $42 \%$ or less complained of gastrointestinal disorders (abdominal pain, nausea, vomiting and diarrhoea). The lack of signs or symptoms in more than $50 \%$ of patients with trichinellosis in the early phase of the infection (i.e. in the first 710 days after infected meat consumption) clearly lays the problem for an early diagnosis and treatment. In addition, the gastrointestinal disorders related to a Trichinella infection are not pathognomonic, they are generally moderate or benign, and it is rare that they arrive at the care of the physician and, when it occurs, unlikely they are related to trichinellosis by physicians. Complications were detected in nine people and all of them were hospitalised.

The different diagnoses based on clinical and laboratory data during the acute phase of the outbreak and at the follow up, clearly stress the difficulties for the physician to make a correct diagnosis since the seroconversion can occur up to two months after the infection. At the admission (i.e. 15 days post infection), only $42 \%$ of patients showed seroconversion. This is a typical pattern observed in T. britovi-infected people and in people infected with a low number of T. spiralis larvae, and it stresses the low sensitivity of the serological tests available on the market. The sensitivity can be increased at a loss of specificity by homemade tests (e.g. by immunofluorescence using a corpuscular antigen, or by ELISA and immunoblot using a crude soluble antigen), but they should be per- 
formed by skilful personnel, because the interpretation of the results can be difficult and questionable.

Several reasons account for the difficulty to have a reliable diagnosis of trichinellosis apart from serology: 1) due to the invasive nature of a muscle biopsy, only few specimens can be collected, if any, and not always Trichinella larvae are found even in serologically confirmed cases; 2) the delayed appearance of clinical signs and symptoms; 3) people complaining an imaginary symptomatology mimic trichinellosis, in the course of a large outbreak, can muddle physicians; and 4) the lack of knowledge on this helminthic infection by physicians who unlikely experienced it previously. Consequently, the only objective diagnostic approach is the serology with the limit of the delayed seroconversion. These considerations explain, at least in part, why in the present outbreak, highly probable, probable and suspected cases based only on the clinical symptomatology, were not confirmed by serology.

The benzimidazole treatment was started at once when trichinellosis was suspected according to the algorithm suggested by Dypouy-Camet et al. (2002). The latter the treatment is prescribed, the higher the probability that the infected person will harbour viable larvae in their muscles for years, with possible persistent myalgia (Pozio et al., 2003). The need of an early treatment, before the protective collagen capsule around larvae in muscles prevents the efficacy of the antihelminthic treatment, has been emphasised in other studies (Pozio et al., 2001b; Dupouy-Camet et al., 2002; Pozio et al., 2003).

In 1982, in Lebanon, an outbreak of trichinellosis involving 2,456 people has been reported (Olaison \& Ljungstrom, 1992). Two decades later, a large outbreak of trichinellosis occurred in Turkey and affected hundreds of people (Ozdemir et al., 2005). In both outbreaks, raw pork (kebbeh nayyeh in the former and raw meatballs in the later), was the source of infection. These two outbreaks emphasise the need to test swine for Trichinella infection at the slaughtering to guarantee safe food for the consumers, especially in the view of the consumption of raw meat. Although T. britovi is predominantly a sylvatic species, it can infect the human being when farmers fail to rear properly domestic pigs, favouring their contact with wildlife. In this outbreak, the early diagnosis, the alert of health authorities and the identification of the infected meat allowed to stop the spread of the infection.

\section{ACKNOWLEDGEMENTS}

T The work of E. Pozio was in part supported by the TrichiNet work package of the MED-VETNET project of the European Union.

\section{REFERENCES}

Bostan K., AkKaya H., Vurusaner C. \& Aksu H. A case of Trichinella spiralis in a fermented sausage. Acta Parasitologica Turcica, 1999, 23, 194-198.

Cortes-Blanco M., Garcia-Cabanas A., Guerra-Peguero F., Ramos-Aceitero J.M., Herrera-Guibert D. \& MartinezNavarro J. F. Outbreak of Trichinellosis in Caceres, Spain, December 2001-February 2002. Euro Surveillance, 2002, 7 , 136-138.

Dubinsky P., Stefancikova A., Kincekova J., Ondriska F., ReiTERova K. \& Medvedova M. Trichinellosis in the Slovak Republic. Parasite, 2001, 8, 100-102.

Dupouy-Camet J., Kociecka W., Bruschi F., Bolas-Fernandez F. \& PozIO E. Opinion on the diagnosis and treatment of human trichinellosis. Expert Opinion of Pharmacotherapy, 2002, 3, 1117-1130.

EISENMAN A. \& EINAT R. A family outbreak of trichinosis acquired in Israel. Harefuah, 1992, 122, 702-704.

Gari-Toussaint M., Tieulié N., Baldin J.L., Marty P., DupouyCamet J., Delaunay P., Fuzibet J.G., Le Fichoux Y. \& Pozio E. Trichinellose à Trichinella britovi dans les Alpes-Maritimes après consommation de viande de sanglier congelée, automne 2003. Bulletin Épidemiologique Hebdomadaire, 2004, 21, 87-88.

Gomez-Garcia V., Hernandez-Quero J. \& Rodriguez-Osorio M. Short report: human infection with Trichinella britovi in Granada, Spain. American Journal of Tropical Medicine and Hygiene, 2003, 68, 463-464.

Grove D. Tissue nematodes (Trichinosis, Drancunculiosis, Filariasis). Principles and Practice of Infectious Diseases. Fifth Edt: Mandell G.L., Bennett J.E., Dolin R., Churchill Livingstone, 2000, Vol. 2, pp. 2943-2950.

Herraez Garcia J., Leon Garcia L.A., Lanusse Senderos C., Cortes Blanco M. \& Garcia Cabanas A. Outbreak of Trichinellosis in the region of la Vera (Carceres, Spain) caused by Trichinella britovi. Annals of Medicine International, 2003, 20, 63-66.

lopez Hernandez B., Velasquez de Castro M.T., Galicia Garcia M.D. \& SABONET J.C. Outbreak of Trichinella britovi infection in Granada in the spring of 2000. Revista Espanola Salud Publica, 2000, 75, 337-344.

Merdivenci A., Aleksanyan V., Girisken G. \& Perk M. An outbreak of Trichinella spiralis infection in man and wild pig in Turkey. Istanbul Universitesi Veteriner Fakultesi Dergisi, 1977, 3 (1-2), 46-71.

NAZLi B. \& InAL T. The occurrence of Trichinella spiralis in domestic and wild pigs and in prepared pork products in Turkey. Berlin Münch Tierärztl Wochenschr, 1987, 100, 187-190.

Nezri M., Ruer J., De Bruyne A., Cohen-Velensi R., Pozio E. \& Dupouy-CAMET J. Premiere observation d'un cas de humain de trichinellose à Trichinella britovi en Algérie apres consommation de viande de chacal (Canis aureus). Bulletin de la Societé de Pathologie Exotique (in press).

Olasion L. \& LJUngSTROM I. An outbreak of trichinosis in Lebanon. Transactions of Royal Society of Tropical Medicine and Hygiene, 1992, 86, 658-660. 
Ozdemír D., Ozkan H., AkKoc N., Onen F., Gurler O., Sarí I., Akar S., Bírlík M., Karg1 A., Ozer E. \& Pozio E. Acute trichinellosis in children compared with adults. Pediatric Infectious Disease Journal, 2005, 24, 897-900.

PozIo E. Factors affecting the flow among domestic, synanthropic and and sylvatic cycles of Trichinella. Veterinary Parasitology, 2000, 9, 241-262.

Pozio E., Gomez-Morales M.A. \& Dupouy-Camet J. Clinical aspects, diagnosis and treatment of trichinellosis. Expert Review Anti-infection Therapy, 2003, 1, 89-100.

Pozio E., La Rosa G. \& Gomez Morales M.A. Epidemiology of human and animal trichinellosis in Italy since its discovery in 1887. Parasite, 2001a, 8, S106-S108.

Pozio E., Pagani P., Marucci G., Zarlenga D.S., Hoberg E.P., De Meneghi D., La Rosa G. \& Rossi L. Trichinella britovi etiological agent of sylvatic trichinellosis in the Republic of Guinea (West Africa) and a re-evaluation of geographical distribution for encapsulated species in Africa. International Journal for Parasitology, 2005, 35, 955-960.

Pozio E., Sacchini D., Sacchi L., TAmburrini A. \& Alberici F. Failure of mebendazole in treating Trichinella spiralis infection in humans at the stage of encapsulating larvae. Clinical Infectious Diseases, 2001b, 32, 638-642.

Pozio E. \& ZARLENGA D.S. Recent advances on the taxonomy, systematics and epidemiology of Trichinella. International Journal for Parasitology, 2005, 35, 1191-1204.

Rodriguez E., Rodriguez M., Escalante M., Perteguer M.J., Garcia E., Uberia F.M. \& Garate T. Outbreak of trichinellosis by $T$. britovi in Madrid. p. 370. In: Mas-Coma S., Bargues M.D., Esteban J.G. \& Valero M.A. (ed.), IX ${ }^{\text {th }}$ European Multicolloquium of Parasitology, 2004, Valencia, Spain.

Rodriguez-Osorio M., Gomez-Garcia V., Benito R. \& Gil J. Trichinella britovi human infection in Spain: Antibody response to surface, excretory/secretory and somatic antigens. Parasite, 2003, 10, 159-164.

Reçu le 13 mai 2005 Accepté le 4 novembre 2005 